\title{
High-viscosity carboxymethylcellulose reduces carbachol-stimulated intestinal chloride secretion in weaned piglets fed a diet based on skimmed milk powder and maltodextrin
}

\author{
Jean-Paul Lallès*, Gaëlle Boudry, Christine Favier and Bernard Sève \\ Unité Mixte de Recherche Systèmes d'Elevage, Nutrition Animale et Humaine (SENAH), INRA-Agrocampus Rennes, \\ Domaine de la Prise, 35590 Saint-Gilles, France
}

(Received 1 March 2005 - Revised 28 October 2005 - Accepted 15 November 2005)

\begin{abstract}
High-viscosity carboxymethylcellulose (CMC) promotes gastrointestinal disorders, tissue alterations and bacterial overgrowth in pigs. The impact of $\mathrm{CMC}$ on intestinal absorptive and secretory physiology is not known. We hypothesised that CMC consumption alters intestinal Na-dependent glucose absorption and stimulates electrogenic chloride secretion. For testing this hypothesis, twenty-four piglets were weaned at $21 \mathrm{~d}$ of age and pair-fed for $13 \mathrm{~d}$ a starter diet based on skimmed milk powder and maltodextrin containing cellulose (control) or CMC. Body weight and faecal total aerobe and coliform counts were measured kinetically. At slaughter, digesta were weighed and characterised for viscosity and pH. Gastrointestinal tissues were weighed and sampled for physiology in Ussing chambers, morphometry and enzymology. Glucose absorption tended to be higher $(P=0.08)$ and carbachol-stimulated chloride secretion was lower $(P=0.01)$ with CMC in the small intestine, without changes in the colon. Aerobes were transiently higher at day $7(P<0.05)$ but coliform counts remained unchanged $(P=0.78)$ and $\beta$-haemolitic Escherichia coli were virtually absent. Stomach and small-intestinal segments were heavier, and viscosity higher with $\mathrm{CMC}(0.001<P<0.05)$. The $\mathrm{pH}$ in the stomach was higher, and in the caecum and proximal colon lower with CMC $(0 \cdot 001<P<0 \cdot 05)$. Jejunal villus area was slightly reduced with CMC $(P<0.05)$ without effects on enzyme activities $(P>0 \cdot 10)$. In conclusion, CMC supplementation had pro-absorptive effects on the small intestine, possibly due to the absence of pathogenic E. coli in the present study.
\end{abstract}

Pigs: Carboxymethylcellulose: Intestinal physiology: Bacteria

Post-weaning colibacillosis is an important infectious disease occurring in pigs 3-10 d after weaning (Hampson, 1994). It involves primarily $\beta$-haemolytic enterotoxigenic Escherichia coli strains that adhere to the proximal intestinal villous enterocytes and release enterotoxins that stimulate hydro-mineral secretion leading to diarrhoea (Francis, 2002). Disease expression is influenced by dietary factors. A diet based on cooked rice and animal protein sources is protective (McDonald et al. 1999), while pearl barley and wheat to a lesser extent exacerbate diarrhoea and the faecal excretion of E. coli (Hopwood et al. 2002, 2004; Montagne et al. 2004). These ingredients are rich in soluble viscous NSP responsible for the increase in digesta viscosity and appearance of colibacillosis. Diet digestibility, nutrient absorption and growth rate are usually reduced with such diets (Hopwood et al. 2002, 2004; Montagne et al. 2004).

Soluble non-digestible NSP including guar gum, high-methylated citrus pectin and carboxymethylcellulose (CMC) have been used as model compounds to increase viscosity and to explore its influence on gastrointestinal function in rats (Blackburn \& Johnson, 1981), chickens (van der Klis et al. 1993a,b; Smits et al. 1997, 1998; Langhout et al. 1999, 2000) and pigs (McDonald et al. 1999, 2001; Montagne et al. 2004). The bulk of digesta was usually increased along the gut while digestion and nutrient absorption were reduced. Alterations in small-intestinal architecture were also noted. In birds, it was clearly demonstrated that the intestinal microflora mediated the magnitude of disorders, since germ-free chicks displayed neither reduced digestibility nor intestinal tissue alterations (Langhout et al. 2000). From these data it is usually considered that NSP reduce the absorption of glucose and water from the small intestine, favouring diarrhoea. However, previous reports showed that all these compounds do not behave similarly on gut physiology. Pectin and other plant gums inhibit solute and water absorption (Blackburn \& Johnson, 1981; Flourie et al. 1984; Rainbird et al. 1984), while medium-viscosity CMC stimulates it in the rat jejunum (Go et al. 1994). The actual effects of polysaccharide compounds on intestinal physiology appear to depend on their chemical structure and rheological properties (Go et al. 1994; Wapnir et al. 1997). Since these mechanisms have not been studied in pigs fed a diet supplemented with CMC, we designed the present experiment. Based on the work by McDonald et al. (2001) in weaned pigs, we hypothesised that the addition of high-viscosity CMC decreases Na-dependent glucose absorption and possibly stimulates chloride secretion in the small 
intestine. We also looked at the physiology of the large intestine because of its pivotal role in gut electrolyte and water reabsorption. A first account of this work has been reported elsewhere (Lallès et al. 2003).

\section{Materials and methods}

All the reagents used were from Sigma (Saint Quentin Fallavier, France).

\section{Diet and feeding}

The detailed composition of the experimental diets has been published recently (Piel et al. 2005). Briefly, they were highly digestible semi-synthetic diets based on maltodextrin, skimmed-milk protein and fish protein. The control diet contained $40 \mathrm{~g}$ cellulose $/ \mathrm{kg}$ air-dried diet and had a viscosity of $7.5($ SEM 0.4$) \mathrm{mPa} \times \mathrm{s}(n 4)$ (see viscosity measurements later). In the $\mathrm{CMC}$ diet, high-viscosity $\mathrm{CMC}$ as used by McDonald et al. (2001) was substituted for cellulose (40 g/kg). The CMC diet had a viscosity of 33.7 (SEM 0.5) $\mathrm{mPa} \times \mathrm{s}$ $(n 4)$. The two diets were formulated to meet weaner pig requirements for growth (Sève, 1994) and were similar in crude protein $(185 \mathrm{~g} / \mathrm{kg} \mathrm{DM})$ and net energy $(11.83 \mathrm{MJ} / \mathrm{kg})$ contents. The diets contained neither antibiotics nor alternative antimicrobial substances. The experimental diets were fed twice daily as a mash (feed-water; 4:3, w/w) for $13 \mathrm{~d}$. Water was freely available throughout the trial.

\section{Animals, experimental design and sample collection}

The experiment was conducted under the guidelines of the French Ministry of Agriculture for animal research. Twenty-four piglets (Pietrain $\times($ Landrace $\times$ Large-White $))$ from the experimental herd of INRA Saint-Gilles with a mean body weight of 6.03 (SEM 0.04) $\mathrm{kg}$ were weaned at age $21 \mathrm{~d}$. At weaning (day 0), twenty-four piglets in two rounds were associated by pairs within litters, with one animal for each diet, on the basis of weaning body weight and litter origin. They were placed into individual cages $(0.6 \times 0.8 \mathrm{~m})$ and were pair-fed until the end of the experimental period. More precisely, the first piglet offered ad libitum access to the food in a given pair was the one having consumed the least during the previous meal, irrespective of the treatment group assigned. The consistency of faeces was visually determined daily up to day 13 after the start of the experiment. It was scored from 1 to 3, 1 corresponding to normal, 2 to soft and 3 to liquid faeces. The faeces were also collected at days $0,5,7$ and 12 for counting total aerobes and coliforms.

At the end of the experimental period, $2 \mathrm{~h}$ after the last meal, the piglets were anaesthetised by electronarcosis, and killed by exsanguination. The gastrointestinal tract was removed and the stomach, small intestine, caecum and colon were isolated by double ligation. Then, the small intestine and colon were dissected and each segment divided into two parts equal in length. Each gastrointestinal segment was weighed full and empty, digesta collected totally and $\mathrm{pH}$ measured. Approximately $10 \mathrm{~g}$ digesta per segment were collected for viscosity measurements.
Tissues were sampled in the middle of the first half of the small intestine and colon for physiology measurements in Ussing chambers (Boudry et al. 2004). Each sample was rinsed with saline $(9 \mathrm{~g} \mathrm{NaCl} / \mathrm{l})$ before treatment. Tissue samples were also collected from the middle of the first and second half of the small intestine (that is, at 25 and $75 \%$ of its length) for villus and crypt morphometry and mucosal enzyme activities. Briefly, the specimens for morphometry $(0.5 \times 0.5 \mathrm{~cm})$ were excised, rinsed in physiological saline and fixed in phosphate-buffered formalin $(10 \%$; $\mathrm{pH} 7 \cdot 6)$ overnight and then rinsed with, and transferred to, ethanol-water (3:1, v/v) until analysis (Salgado et al. 2001). The samples for enzymology determination were rinsed with saline, scraped with a glass slide at $+4^{\circ} \mathrm{C}$ and stored at $-80^{\circ} \mathrm{C}$ until analysis (Salgado et al. 2001).

\section{Counts of total aerobes, coliforms and $\beta$-haemolytic Escherichia coli in the faeces}

Freshly collected faecal samples (1 g) were immediately placed in Ringer solution, homogenised, and analysed within 3 to $4 \mathrm{~h}$. Serial ten-fold dilutions of the homogenates were prepared and $0.1 \mathrm{ml}$ of $10^{1}$ to $10^{6}$ dilutions were spread on two agar plates. The first one was Columbia blood agar and served for the determination of total aerobes while the second was MacConkey agar, a specific medium for counting total coliforms (Canibe \& Jensen, 2003). Colonies were counted after 48 and $24 \mathrm{~h}$, respectively, of incubation at $37^{\circ} \mathrm{C}$ under aerobic conditions. $\beta$-Haemolytic E. coli colonies were identified after $24 \mathrm{~h}$ on blood agar plates, based on their morphology. Data are expressed as log colony-forming units $(\mathrm{CFU}) / \mathrm{g}$ faeces.

\section{$p H$ and viscosity measurements}

Digesta $\mathrm{pH}$ was determined immediately after slaughter on fresh digesta using a pH meter (704 model; Metrohm Ltd, Herisau, Switzerland). Viscosity measurements were carried out on diets in the form of mash and diluted digesta at a shear rate of 60/s (Piel et al. 2005), as recommended by McDonald et al. (2001).

\section{Measurements of electrical parameters of the small-intestinal} mисова

Electrophysiological properties of the small-intestinal mucosa were measured in twelve Ussing chambers as described elsewhere (Boudry et al. 2004). Each set of measurements included samples from a given experimental pair of piglets, which were slaughtered at a $15 \mathrm{~min}$ interval. Three pieces per intestinal site per piglet were assigned randomly to chambers. The transepithelial potential difference of the intestinal tissue was clamped at $0 \mathrm{mV}$ by an external current, this being equal to the short-circuit current $\left(\mathrm{I}_{\mathrm{sc}}\right)$. The transepithelial resistance (R) was calculated from Ohm's law from current deflections in response to $3 \mathrm{mV}$ transepithelial voltage pulses of $300 \mathrm{~ms}$ every $10 \mathrm{~s}$ (Boudry et al. 2004). The bathing medium in the Ussing chambers was Ringer's bicarbonate solution containing $16 \mathrm{mM}$-D-glucose on the serosal side or $16 \mathrm{~mm}$-mannitol on the mucosal side for tissues from the small intestine and $16 \mathrm{~mm}-\mathrm{D}$-glucose on both sides 
for tissues from the proximal colon. The medium was continuously bubbled with carbogen $\left(5 \% \mathrm{CO}_{2}: 95 \% \mathrm{O}_{2}\right)$ and maintained at $38^{\circ} \mathrm{C}$. Tissues were left to equilibrate for $20 \mathrm{~min}$ before basal $\mathrm{I}_{\mathrm{sc}}$ and $\mathrm{R}$ were evaluated as the mean values from 20 to $30 \mathrm{~min}$. Glucose absorption by small-intestinal tissues was assessed through the increase in $\mathrm{I}_{\mathrm{sc}}\left(\Delta \mathrm{I}_{\mathrm{sc}}\right)$ after mucosal addition of $16 \mathrm{~mm}-\mathrm{D}$-glucose osmotically balanced on the serosal side by $16 \mathrm{~mm}$-mannitol. Secretagogue-induced chloride secretion was studied by the addition of $10^{-3} \mathrm{M}$-carbachol, $10^{-4} \mathrm{M}$-serotonin (5-HT), or $10^{-4} \mathrm{M}$ histamine in the serosal compartment of separate chambers, followed $10 \mathrm{~min}$ later by $2.2 \times 10^{-3} \mathrm{M}$-theophylline in both sides of each chamber. Mean responses for each set of three measurements for each tissue type were calculated for theophylline.

\section{Morphology and enzyme activities of the small-intestinal mucosa}

Samples of small intestine were microdissected for villi and crypts and measured according to the technique of Goodlad et al. (1991). This was carried out on ten to fifteen villi and crypts per sample using the equipment described previously (Piel et al. 2005). The obtained values were averaged per villi and crypts for each tissue sample.

The activities of maltase (EC 3.2.1.20), aminopeptidase A (EC 3.4.11.7), dipeptidylpeptidase IV (EC 3.4.14.5) and alkaline phosphatase (EC 3.1.3.1) were determined and specific activities calculated as detailed previously (Salgado et al. 2001).

\section{Statistical analysis}

The variance homogeneity of the data was assessed by $F$ test using Statview (version 4.55; Abacus Concepts Inc., Berkeley, CA, USA). Data were analysed using the general linear models procedure of the Statistical Analysis System (SAS, 1989). The effect of replication was tested using the residual variation between pairs as the error. The effect of the diet was tested against residual variations within pairs as the error term. Student's $t$ test was used for comparisons of least square means. Data from variables measured over time were analysed for time, diet and time $\times$ diet interaction using the REPEATED statement within the general linear models procedure of SAS. Values are presented as least square means and SEM. Differences were declared significant at $P<0.05$.

\section{Results}

\section{Technical results}

As already reported (Piel et al. 2005), a pair of piglets had to be removed from the study because one animal consumed abnormally low amounts of mash. Pair-feeding led to essentially similar slaughter body weights (8.67 (SEM 0.14) and 8.88 (SEM 0.14) kg; $P=0.30$ ) and body-weight gains $(2.70$ (SEM 0.14 ) and 2.88 (SEM $0 \cdot 14) \mathrm{kg} ; P=0.38$ ) among piglets fed the control and $\mathrm{CMC}$ diets, respectively. The faecal scores were significantly higher in the $\mathrm{CMC}$ than in the control group from day 6 to day $13(P<0 \cdot 0001)$ (Fig. 1).

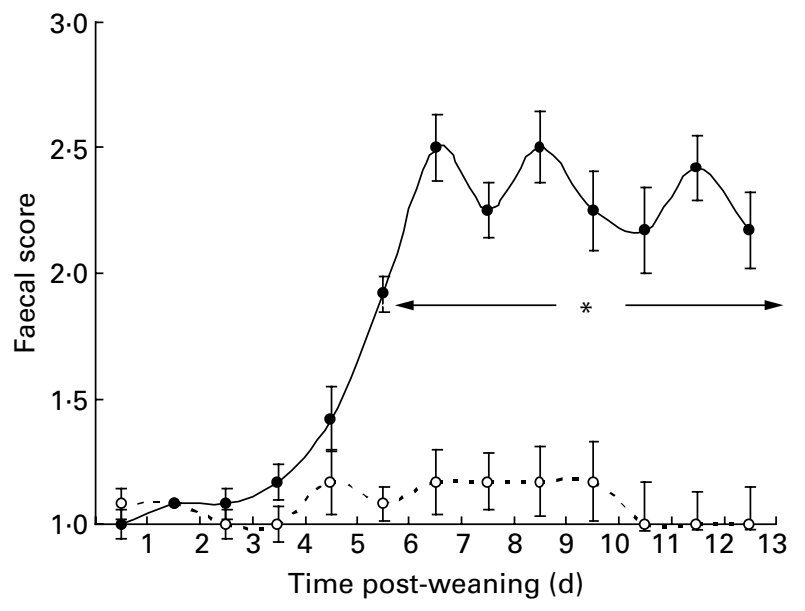

Fig. 1. Influence of the diet on faecal scores (see this page) in piglets fed a control diet (-O-) or a diet containing carboxymethylcellulose (CMC) (-๑) for $13 \mathrm{~d}$ post-weaning. Values are least square means, with their standard errors represented by vertical bars. *Faecal scores were significantly higher in the CMC as compared with the control piglets between day 6 and day 13 post-weaning $(P<0.0001)$.

Counts of coliforms, aerobes and $\beta$-haemolytic Escherichia coli in the faeces

Coliform counts (log CFU/g) in the faeces of piglets did not vary significantly over time post-weaning and between treatments (8.17 (SEM 0.13) and 8.12 (SEM 0.12) log CFU/g, for control and $\mathrm{CMC}$-fed piglets, respectively; $P=0.78$ ). A significant time $\times$ treatment interaction was observed for aerobe counts $(P=0.03)$, showing transiently higher values in the CMC group at day $7(P=0.05)$ (Fig. 2). The coliform:aerobe count ratio was not influenced by the diet $(P=0 \cdot 36)$. Only one faecal sample from a CMC pig was found to harbour $\beta$-haemolytic $E$. coli in the present study.

Weight and characteristics of gut segments and digesta at slaughter

The weight of the full gastrointestinal segments was lower for the stomach and higher for the second half and whole small

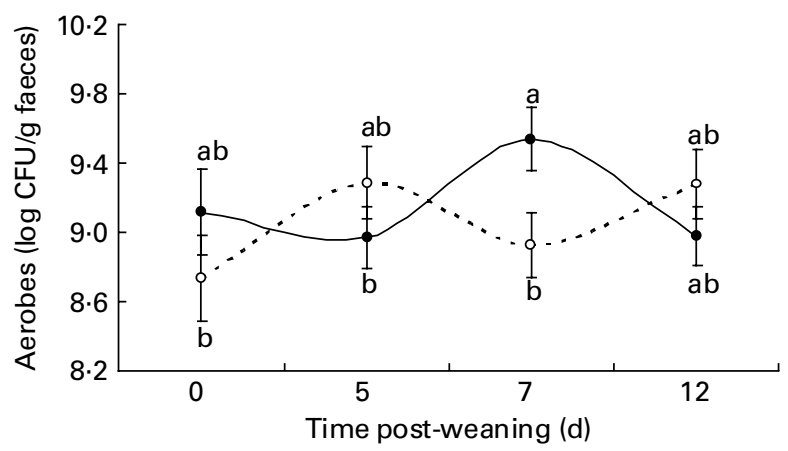

Fig. 2. Influence of the time post-weaning and diet on the counts of total aerobes (log colony-forming units (CFU)/g) in the faeces of piglets fed a control diet (-O-) or a diet containing carboxymethylcellulose $(--)$ for $13 \mathrm{~d}$. Values are least square means, with their standard errors represented by vertical bars. ${ }^{a, b}$ Mean values with unlike letters were significantly different $(P \leq 0.05)$. 
intestine of the CMC piglets $(P<0 \cdot 05)$, with no significant effects of treatments for the first half of the small intestine and large intestine $(P=0.92$ and $P=0.47$, respectively) (Table 1). The amount of mash consumed during the last meal before slaughter was similar in both treatment groups $(P=0 \cdot 19)$. However, $2 \mathrm{~h}$ later, the weight of fresh digesta in the stomach was slightly $(-8 \%)$ but significantly lower in the CMC group as compared with the control $(P=0 \cdot 02)$. Conversely, this amount of contents was higher in the small intestine of CMC piglets $(P=0 \cdot 01)$. This tended to be accounted for by the amount of digesta present in the second half of the small intestine (73 (SEM 12) and 108 (SEM 13) g; $P=0.08$ ). No significant differences between diets were observed for large-intestinal digesta weights $(P=0.53)$.

As expected from the differences observed between diets, the viscosity of digesta in the stomach, the first and second halves of the small intestine and in the caecum were 10 $(P=0.001), 1.7 \quad(P=0.01), 13 \quad(P=0.01)$ and $2.6 \quad(P=0.03)$ times higher in the CMC piglets than in the controls (Table 2). The viscosity of digesta in the colon was not measurable after dilution as applied to the digesta of the other gastrointestinal segments.

The $\mathrm{pH}$ of digesta was higher in the stomach $(P=0.03)$ and lower in the caecum $(P=0.001)$ and colon $(P=0.001)$ of the piglets fed the CMC diet (Fig. 3). No significant differences were observed between treatments in the first and second half of the small intestine and in the second half of the colon for digesta $\mathrm{pH}(P=0.84, P=0.26$ and $P=0.49$, respectively).

\section{Absorptive and secretory properties of the intestinal mucosa}

The mucosa of the first half of the small intestine displayed a basal $\mathrm{I}_{\mathrm{sc}}$ and a transepithelial resistance that were not significantly different between diet treatments $(P=0.22$ and $P=0.13$, respectively) (Table 3). However, the increase in $\mathrm{I}_{\mathrm{sc}}$ in response to glucose tended to be higher in the piglets fed CMC than in the controls $(P=0.08)$. The change in $\mathrm{I}_{\mathrm{sc}}$ to carbachol stimulation was $60 \%$ lower in the $\mathrm{CMC}$ piglets $(P<0 \cdot 001)$. By contrast, mucosal responses to 5-HT, histamine and theophylline did not significantly differ between treatments $(P=0.73, P=0.87$ and $P=0 \cdot 54$, respectively). No significant differences between diets were observed in these physiology parameters for the colonic mucosa $(P=0.23$ to $P=0.97)$.

\section{Morphometry and enzyme activities of the small-intestinal mucosa}

There was no significant difference between treatments in intestinal length and width of villi and crypts $(P=0.15$ to $P=0.76$ ), except villus area in the first half of the small intestine that was lower with CMC as compared with the control (102 546 (SEM 4500) and 87705 (SEM 4500) $\mu^{2}$; $P=0.04)$. There was no significant difference between treatments in any of the intestinal specific enzyme activities studied $(P=0.25$ to $P=0.94)$.

\section{Discussion}

\section{Carboxymethylcellulose and intestinal absorptive and secretory physiology}

The major result of the present study is that high-viscosity CMC tended to increase Na-dependent glucose absorption and drastically decreased carbachol-induced chloride secretion in the jejunum of pigs, without any significant changes at the level of the proximal colon. Our Ussing chamber data are in agreement with previously published values (Boudry et al. 2004). Thus, the small intestine of our piglets was in a rather pro-absorptive state for ions and water, with no influence of CMC on the large intestine. Faecal scores were clearly increased after $5 \mathrm{~d}$ of $\mathrm{CMC}$ consumption and remained high thereafter, in agreement with increased ileal water content in these piglets (Piel et al. 2005). Faeces inconsistency might have reflected the water-holding and gelling capacities of $\mathrm{CMC}$, which were maintained in the faeces since CMC is not fermented (Wyatt et al. 1988; McDonald et al. 2001). Increased water consumption often seen with CMC

Table 1. Influence of the diet on the weight of the full segments and of fresh digesta $(\mathrm{g})$ in the gastrointestinal tract of piglets fed a control diet or a diet containing carboxymethylcellulose (CMC)

(Least square means with their standard errors)

\begin{tabular}{|c|c|c|c|c|c|}
\hline \multirow[b]{2}{*}{ Diet... } & \multicolumn{2}{|c|}{ Control } & \multicolumn{2}{|c|}{$\mathrm{CMC}$} & \multirow[b]{2}{*}{ Statistical significance of a diet effect: $P$} \\
\hline & Mean & SEM & Mean & SEM & \\
\hline \multicolumn{6}{|l|}{ Weight of the full segments } \\
\hline Stomach & 593 & 9 & 558 & 9 & 0.02 \\
\hline Small intestine, first half & 234 & 8 & 235 & 8 & 0.92 \\
\hline Small intestine, second half & 264 & 11 & 305 & 11 & 0.02 \\
\hline Small intestine, total & 498 & 11 & 543 & 13 & 0.03 \\
\hline Large intestine & 216 & 15 & 199 & 17 & 0.47 \\
\hline \multicolumn{6}{|c|}{ Weight of mash consumed and of fresh digesta } \\
\hline Mash consumed & 564 & 4 & 571 & 4 & 0.19 \\
\hline Stomach & 529 & 9 & 493 & 9 & 0.02 \\
\hline Small intestine, first half & 47 & 7 & 58 & 7 & $0 \cdot 27$ \\
\hline Small intestine, second half & 73 & 12 & 108 & 13 & 0.08 \\
\hline Small intestine, total & 120 & 9 & 168 & 11 & 0.01 \\
\hline Large intestine & 118 & 13 & 105 & 15 & 0.53 \\
\hline
\end{tabular}

For details of diets and procedures, see p. 489 
Table 2. Influence of the diet on the viscosity (mPa.s) of gut digesta of piglets fed a control diet or a diet containing carboxymethylcellulose (CMC)

(Least square means with their standard errors)

\begin{tabular}{lcccccc}
\hline & \multicolumn{2}{c}{ Control } & & \multicolumn{2}{c}{ CMC } & \\
\cline { 2 - 3 } Diet... & Mean & SEM & & Mean & SEM & Statistical significance of a diet effect: $P$ \\
\hline Stomach & 3.2 & 4.3 & & 31.9 & 4.3 & 0.001 \\
Small intestine, first half & 1.4 & 0.2 & 2.4 & 0.2 & 0.001 \\
Small intestine, second half & 1.3 & 3.4 & 17.5 & 3.0 & 0.001 \\
Caecum & 2.8 & 0.5 & 7.3 & 0.6 & 0.03 \\
\hline
\end{tabular}

For details of diets and procedures, see p. 489

supplementation (Smits et al. 1997; Langhout et al. 1999, 2000) might have also contributed to the water retained by CMC in the digesta and to the increased faecal water losses.

Improved Na-dependent glucose absorption in the present study is in agreement with the observation that medium-viscosity CMC increased absorption of $\mathrm{Na}$ and water in the perfused jejunum of both control rats and those with induced osmotic diarrhoea (Go et al. 1994). These authors considered that the rise in viscosity associated with the addition of CMC may have increased surface contact of osmotically active solutes, resulting in greater net water absorption. They also suggested the possibility that CMC causes local changes of the unstirred layer, following accumulation by physical entrapment or chemical link of CMC to the intestinal glycocalyx. The molecular mechanisms for increased $\mathrm{Na}$-glucose absorption as observed in the present study are not known. They did not seem to be related to villus surface area, which was reduced with CMC. Other explanations include microvillus elongation as observed following fasting in rats (Waheed \& Gupta, 1997), increased density of the Na-glucose co-transporter SGLT1 or increased absorption via other routes (Ferraris, 2001). Finally, decreased jejunal absorption of glucose and water has been reported with guar gum (Blackburn \& Johnson, 1981; Rainbird et al. 1984). Differences in

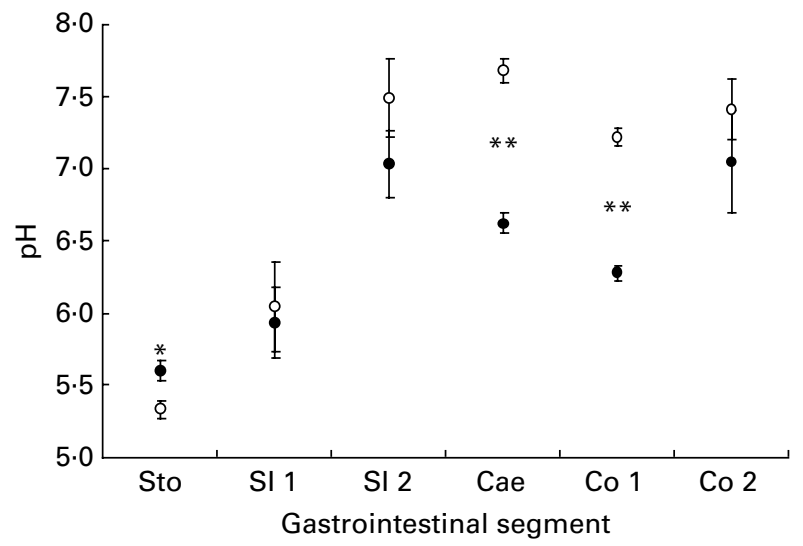

Fig. 3. Influence of the diet on digesta $\mathrm{pH}$ at slaughter in piglets fed a control diet $(\bigcirc)$ or a diet containing carboxymethylcellulose $(\bullet)$ for $13 \mathrm{~d}$. Values are least square means, with their standard errors represented by vertical bars. Sto, stomach; SI 1, first half of the small intestine; SI 2, second half of the small intestine; Cae, caecum; Co 1, first half of the colon; Co 2, second half of the colon. *Digesta $\mathrm{pH}$ was significantly higher in the stomach of the CMC pigs $(P=0.03)$. ${ }^{*}$ Digesta $\mathrm{pH}$ was significantly higher in the caecum and proximal colon of the control pigs $(P=0.001)$. physiological effects between NSP, including CMC, might have come from differences in structural and rheological properties (Go et al. 1994; Wapnir et al. 1997).

The predominant electrolyte driving fluid secretion is chloride, although secretion of bicarbonate and $\mathrm{K}$ occurs along the intestine (Barrett \& Keely, 2000). Chloride secretion augments in response to increases in cyclic nucleotides (for example, cyclic AMP) or cytosolic Ca through two types of channels, cystic fibrosis transmembrane conductance regulator and $\mathrm{Ca}^{2+}$-activated chloride channel, respectively. These channels can be stimulated by various substances including neurotransmitters (acetylcholine, carbachol), immune (for example, histamine) and paracrine (for example, 5-HT) mediators, and exogenous agents such as bacteria and bacterial toxins. In the present study, only the carbachol-induced chloride secretion of the jejunum was reduced with the CMC diet. Carbachol is a cholinergic muscarinic agonist acting through the increase of intracellular $\mathrm{Ca}$ ion concentration (Dharmsathaphorn \& Pandol, 1986). The responses to 5-HT and histamine, two other mediators of the intracellular Ca pathway (Barrett \& Keely, 2000), remained unchanged. Thus, CMC may have acted at the level of the muscarinic receptor. The cyclic AMP-dependent chloride secretion was apparently not involved in the observed changes, as revealed by the lack of differences between treatments in response to the agonist theophylline. The cyclic AMP-dependent cystic fibrosis transmembrane conductance regulator chloride channel is considered as the major pathway for chloride movement (Barrett \& Keely, 2000). Therefore, it is possible that the reduced jejunal chloride secretory capacity via the intracellular $\mathrm{Ca}$ route in presence of CMC as observed in the present study would not be sufficient to counter electrogenic chloride secretion stimulated by $E$. coli enterotoxins via the cyclic AMP-dependent pathway in post-weaning colibacillosis.

\section{Carboxymethylcellulose and the intestinal microflora}

Many data in rats and birds support the view that the intestinal microflora, especially E. coli, mediates the magnitude of the adverse effects of high-viscosity NSP (Wyatt et al. 1988; Smits et al. 1997, 1998; Langhout et al. 1999). In pigs, high-viscosity CMC favours the outgrowth of intestinal enteropathogenic $\beta$-haemolytic E. coli (McDonald et al. 2001; Hopwood et al. 2002). In the present study, total aerobes in the faeces only transiently increased with CMC while $E$. coli counts did not vary significantly and $\beta$-haemolytic E. coli were virtually absent. Haemolytic E. coli fimbriae 
Table 3. Influence of the diet on the electrophysiological parameters measured in Ussing chambers for the first half of the small intestine of piglets fed a control diet or a diet containing carboxymethylcellulose (CMC) (Least square means with their standard errors)

\begin{tabular}{|c|c|c|c|c|c|}
\hline \multirow[b]{2}{*}{ Diet... } & \multicolumn{2}{|c|}{ Control } & \multicolumn{2}{|c|}{ CMC } & \multirow[b]{2}{*}{ Statistical significance of a diet effect: $P$} \\
\hline & Mean & SEM & Mean & SEM & \\
\hline $\mathrm{I}_{\mathrm{sc}}\left(\mu \mathrm{A} / \mathrm{cm}^{2}\right)$ & 56 & 17 & 88 & 17 & 0.22 \\
\hline Transepithelial resistance $\left(\Omega \times \mathrm{cm}^{2}\right)$ & 49 & 6 & 35 & 6 & 0.13 \\
\hline$\Delta \mathrm{l}_{\text {sc }}$ glucose $\left(\mu \mathrm{A} / \mathrm{cm}^{2}\right)$ & 158 & 33 & 256 & 33 & 0.08 \\
\hline$\Delta \mathrm{I}_{\mathrm{sc}}$ carbachol $\left(\mu \mathrm{A} / \mathrm{cm}^{2}\right)$ & 81 & 9 & 32 & 9 & 0.01 \\
\hline$\Delta \mathrm{l}_{\mathrm{sc}} 5-\mathrm{HT}\left(\mu \mathrm{A} / \mathrm{cm}^{2}\right)$ & 57 & 5 & 54 & 4 & 0.73 \\
\hline$\Delta \mathrm{I}_{\mathrm{sc}}$ histamine $\left(\mu \mathrm{A} / \mathrm{cm}^{2}\right)$ & 70 & 21 & 65 & 19 & 0.87 \\
\hline$\Delta \mathrm{I}_{\mathrm{sc}}$ theophylline $\left(\mu \mathrm{A} / \mathrm{cm}^{2}\right)$ & 115 & 31 & 144 & 31 & 0.54 \\
\hline
\end{tabular}

$\mathrm{I}_{\mathrm{sc}}$, short-circuit current.

For details of diets and procedures, see p. 489.

attach to specific receptors expressed on villus epithelial cells and whose presence varies between individuals and breeds (Baker et al. 1997). The occurrence of post-weaning colibacillosis strongly depends on the presence of such receptors (Madec et al. 2000). In the present study, our piglets possibly did not bear these receptors and, therefore, were unable to bind pathogenic E. coli. This would be consistent with the lack of marked alterations in intestinal architecture and enzyme activities, the lack of increased chloride secretory capacity, and the unaltered growth and ileal digestibility of nutrients in our CMC pigs (present results; Piel et al. 2005). Langhout et al. (2000), using germ-free chicks, demonstrated that the intestinal microflora contributes to increased digesta viscosity and small-intestinal alterations, and to reduced nutrient digestibility in the small intestine and faeces of birds. Whether bacterial adhesion of pathogenic E. coli to intestinal epithelial cells is influenced by NSP is not known. However, a recent study showed that $\mathrm{CMC}$ drastically inhibited the adhesion of E. coli $\mathrm{K} 88$ (isolated from swine intestine) to Caco-2 cells in vitro (Sugita-Konishi et al. 2004). Also, mice infected with Salmonella had a survival rate much higher when supplemented with CMC (Sugita-Konishi et al. 2004). The chelating properties of CMC may be involved in the protective mechanisms since chelating agents are inhibitors of several bacterial adhesins and CMC inhibits strongly the adhesion of E. coli to Saccharomyces cerevisiae (Taweechaisupapong \& Doyle, 2000).

\section{Carboxymethylcellulose and digesta characteristics}

As expected, high-viscosity CMC increased digesta viscosity all along the small and large intestines of our piglets, in agreement with previous studies (Smits et al. 1997; Langhout et al. 1999; McDonald et al. 2001; Hopwood et al. 2002). Gastric $\mathrm{pH}$ was higher and digesta amounts lower in our CMC piglets than in the controls. A higher $\mathrm{pH}$ may have resulted from a reduced secretion of hydrochloric acid and/or an increased dilution by a faster passage rate of the liquid phase, as suggested for gizzard $\mathrm{pH}$ in birds fed CMC (van der Klis et al. 1993a). A faster passage rate of liquid soon after the meal is supported by a lower gastric load as seen at slaughter in the present study. Nevertheless, highly viscous NSP are usually considered to increase the overall mean retention time of digesta in the gastrointestinal tract (van der Klis et al. 1993a) despite increased motility (Cherbut et al. 1990).

McDonald et al. (2001) reported an unexpectedly lower $\mathrm{pH}$ in the large intestine of pigs fed CMC. They suggested that CMC inhibited volatile fatty acid absorption since volatile fatty acid production normally decreases digesta $\mathrm{pH}$ and because CMC is considered as non-fermentable (Wyatt et al. 1988; McDonald et al. 2001). We also noted a lower $\mathrm{pH}$ in the caecum and proximal colon. In the digestion part of our research (Piel et al. 2005), we observed similar flows of ileal digesta and, therefore, similar loads of undigested material reaching the large intestine, with both treatments, suggesting potentially similar fermentation profiles in the caecum and proximal colon between diets. Altogether, the present results support the hypothesis that $\mathrm{CMC}$ inhibits volatile fatty acid absorption (McDonald et al. 2001).

\section{Diet composition, digesta viscosity and bacterial overgrowth}

Australian studies have consistently shown that a highly digestible diet based on cooked white rice and animal protein is able to limit intestinal proliferation of pathogenic E. coli and to protect weaned pigs against colibacillosis (McDonald et al. 2001; Hopwood et al. 2002; Montagne et al. 2004). Conversely, diets supplemented with soluble NSP or other indigestible compounds, including guar gum (McDonald et al. 1999), CMC of varying viscosities (McDonald et al. 2001; Hopwood et al. 2002; Montagne et al. 2004), pearl barley alone or supplemented with exogenous enzymes (Hopwood et al. 2004), or mixtures of plant protein sources without or with wheat (Montagne et al. 2004), all predisposed pigs to bacterial overgrowth and colibacillosis. The present diet based on skimmed milk powder and maltodextrin was highly digestible and of low intestinal viscosity (Piel et al. 2005). No proliferation of aerobic bacteria and $\beta$-haemolytic $E$. coli was detected in the faeces of piglets fed high-viscosity CMC. The lack of bacterial proliferation and the protection conferred by a high proportion of dairy products are possible reasons for the absence of colibacillosis in the present study. Australian studies extended their observation of the protective effect of the cooked rice diet against other diseases like swine dysentery caused by the proliferation of Brachyspira hyodysenteriae (Siba et al. 1996; Durmic et al. 1998; Pluske et al. 1998). 
However, this was not confirmed by a recent Danish work (Lindecrona et al. 2003).

\section{Conclusions and implications}

In the present study, the addition of high-viscosity CMC to a highly digestible weaner diet for pigs based on skimmed milk powder and maltodextrin tended to stimulate Na-dependent absorption and reduced intestinal carbachol-induced chloride secretory capacity of the jejunum. This was observed without inducing haemolytic colibacillosis despite increased digesta viscosity. These data support the idea that the degraded faeces consistency after $5 \mathrm{~d}$ of CMC consumption was not the result of intestinal hypersecretion and diarrhoea but of the water-holding and swelling capacities of the high-viscosity $\mathrm{CMC}$ used. Increasing digesta viscosity through the diet is apparently not sufficient to alter intestinal physiology in the absence of pathogenic bacteria in young pigs.

\section{Acknowledgements}

The present study was supported financially by the European Union (project Healthypigut, contract no. QLK5-CT200000522 ) to whom we are grateful. The authors are solely responsible for the work described in this article, and their opinions are not necessarily those of the European Union. The authors wish to thank Patrick Touanel for the care to the animals, all the staff from the slaughterhouse and laboratory for sample collection and treatment, Henri Flageul for technical assistance in the Ussing chamber work, Sandrine Péron for viscosity, osmolality, intestinal morphometry and enzymology measurements, and Jeannine Quillet for gathering the literature.

\section{References}

Baker DR, Billey LO \& Francis DH (1997) Distribution of K88 Escherichia coli-adhesive and non-adhesive phenotypes amongst four breeds. Vet Microbiol 54, 123-132.

Barrett KE \& Keely SJ (2000) Chloride secretion by the intestinal epithelium: molecular basis and regulatory aspects. Annu Rev Physiol 62, 535-572.

Blackburn NA \& Johnson IT (1981) The effect of guar gum on the viscosity of the gastrointestinal contents and on glucose uptake from the perfused jejunum in the rat. Br J Nutr 46, 239-246.

Boudry G, Péron V, Luron I, Lallès JP \& Sève B (2004) Weaning induces transient and long-lasting modifications of absorptive and secretory properties and epithelial barrier function of piglet intestine. J Nutr 134, 2256-2262.

Canibe N \& Jensen BB (2003) Fermented and nonfermented liquid feed to growing pigs: effects on aspects of gastrointestinal ecology and growth performance. J Anim Sci 81, 2019-2031.

Cherbut C, Albina E, Champ M, Doublier JL \& Lecannu G (1990) Action of guar gums on the viscosity of digestive contents and on the gastrointestinal motor function in pigs. Digestion 46, 205-213.

Dharmsathaphorn K \& Pandol SJ (1986) Mechanisms of chloride secretion induced by carbachol in a colonic epithelium cell line. $J$ Clin Invest 77, 348-354.

Durmic Z, Pethick DW, Pluske JR \& Hampson DJ (1998) Changes in bacterial populations in the colon of pigs fed different sources of dietary fibre, and the development of swine dysentery after experimental infection. J Appl Microbiol 85, 574-582.

Ferraris RP (2001) Dietary and developmental regulation of intestinal sugar transport. Biochem J 360, 265-276.

Flourie B, Vidon N, Florent C \& Bernier JJ (1984) Effect of pectin on jejunal glucose absorption and unstirred layer thickness in normal man. Gut 25, 936-941.

Francis DH (2002) Enterotoxigenic Escherichia coli infections in pigs and its diagnosis. J Swine Health Prod 10, 171-175.

Go JT, Harper RG, Sia CG, Teichberg S \& Wapnir RA (1994) Oral rehydration solutions: increased water and sodium absorption by addition of a viscosity-enhancing agent in a rat model of chronic osmotic diarrhea. J Pediatr Gastroenterol Nutr 19, 410-416.

Goodlad RA, Levi S, Lee CY, Mandir N, Hodgson H \& Wright NA (1991) Morphometry and cell proliferation in endoscopic biopsies: evaluation of a technique. Gastroenterology 101, $1235-1241$.

Hampson DJ (1994) Postweaning Escherichia coli in pigs. In Escherichia coli in Domestic Animals and Humans, pp. 171-191 [CL Gyles, editor]. Wallingford: CAB International.

Hopwood DE, Pethick DW \& Hampson DJ (2002) Increasing the viscosity of the intestinal contents stimulates proliferation of enterotoxigenic Escherichia coli and Brachyspira pilosicoli in weaner pigs. Br J Nutr 88, 523-532.

Hopwood DE, Pethick DW, Pluske JR \& Hampson DJ (2004) Addition of pearl barley to a rice-based diet for newly weaned piglets increases the viscosity of the intestinal contents, reduces starch digestibility and exacerbates post-weaning collibacillosis. $\mathrm{Br} \mathrm{J}$ Nutr 92, 419-427.

Lallès JP, Boudry G, Favier C, Montagne L, Piel C \& Sève B (2003) Addition of carboxymethylcellulose to milk-based diets for piglets does not induce diarrhoea and colibacillosis post-weaning. In Proceedings of the 9th International Symposium on Digestive Physiology in Pigs, vol. 2, pp. 192-194 [RO Ball, editor]. Edmonton, Canada: University of Alberta.

Langhout DJ, Schutte JB, de Jong J, Sloetjes H, Verstegen MW \& Tamminga S (2000) Effect of viscosity on digestion of nutrients in conventional and germ-free chicks. Br J Nutr 83, 533-540.

Langhout DJ, Schutte JB, Van Leeuwen P, Wiebenga J \& Tamminga S (1999a) Effect of dietary high- and low-methylated citrus pectin on the activity of the ileal microflora and morphology of the small intestinal wall of broiler chicks. Br Poult Sci 40, 340-347.

Lindecrona RH, Jensen TK, Jensen BB, Leser TD, Jiufeng W \& Moller K (2003) The influence of diet on the development of swine dysentery upon experimental infection. Anim Sci 76, $81-87$.

McDonald DE, Pethick DW, Mullan BP \& Hampson DJ (2001) Increasing viscosity of the intestinal contents alters small intestinal structure and intestinal growth, and stimulates proliferation of enterotoxigenic Escherichia coli in newly-weaned pigs. $\mathrm{Br} J$ Nutr 86, 487-498.

McDonald DE, Pethick DW, Pluske JR \& Hampson DJ (1999) Adverse effects of soluble non-starch polysaccharide (guar gum) on piglet growth and experimental colibacillosis immediately after weaning. Res Vet Sci 67, 245-250.

Madec F, Bridoux N, Bounaix S, Cariolet R, Duval-Yfflah Y, Hampson DJ \& Gestin A (2000) Experimental models of porcine postweaning colibacillosis and their relationship to postweaning diarrhoea and digestive disorders as encountered in the field. Vet Microbiol 72, 295-310.

Montagne L, Cavaney FS, Hampson DJ, Lallès JP \& Pluske JR (2004) Effect of diet composition on post-weaning colibacillosis in piglets. J Anim Sci 82, 2364-2374.

Piel C, Montagne L, Sève B \& Lallès JP (2005) Increasing digesta viscosity using carboxymethylcellulose in weaned piglets stimulates ileal goblet cell numbers and maturation. J Nutr 135, $86-91$. 
Pluske JR, Durmic Z, Pethick DW, Mullan BP \& Hampson DJ (1998) Confirmation of the role of rapidly fermentable carbohydrates in the expression of swine dysentery after experimental infection. J Nutr 128, 1737-1744.

Rainbird AL, Low AG \& Zebrowska T (1984) Effect of guar gum on glucose and water absorption from isolated loops of jejunum in conscious pigs. Br J Nutr 52, 489-498.

Salgado P, Lallès JP, Toullec R, Mourato M, Cabral FM \& Freire JPB (2001) Nutrient digestibility of chickpea (Cicer arietinum L.) seeds and effects on the small intestine of weaned piglets. Anim Feed Sci Technol 91, 197-212.

SAS (1989) SAS/STAT User's Guide: Statistics. version 6 edition, Cary, NC: SAS Institute Inc.

Sève B (1994) Alimentation du porc en croissance: intégration des concepts de protéine idéale, de disponibilité digestive des acides aminés et d'énergie nette (Growing pig nutrition: integration of concepts of ideal protein, digestive dispensability of amino acids and net energy). INRA Prod Anim 7, 275-291.

Siba PM, Pethick DW \& Hampson DJ (1996) Pigs experimentally infected with Serpulina hyodysenteriae can be protected from developing swine dysentery by feeding them a highly digestible diet. Epidemiol Infect 116, 207-216.

Smits CH, Veldman A, VerkadeHJ \& Beynen AC(1998) The inhibitory effect of carboxymethylcellulose with high viscosity on lipid absorption in broiler chickens coincides with reduced bile salt concentration and raised microbial numbers in the small intestine. Poultry Sci 77, 1534-1539.

Smits CH, Veldman A, Verstegen MWA \& Beynen AC (1997) Dietary carboxymethylcellulose with high instead of low viscosity reduces macronutrient digestion in broiler chickens. $J$ Nutr $\mathbf{1 2 7}$, 483-487.

Sugita-Konishi Y, Kobayashi K, Sakanaka S, Juneja LR \& Amano F (2004) Preventive effect of sialylglycopeptide-nondigestive polysaccharide conjugates on Salmonella infection. J Food Agric Chem 52, 5443-5448.

Taweechaisupapong S \& Doyle RJ (2000) Sensitivity of bacterial coaggregation to chelating agents. FEMS Immunol Med Microbiol 28, 343-346.

van der Klis JD, van Voorst A \& van Cruyningen C (1993a) Effect of a soluble polysaccharide (carboxy methyl cellulose) on the physico-chemical conditions in the gastrointestinal tract of broilers. Br Poult Sci 34, 971-983.

van der Klis JD, Verstegen MWA \& van Voorst A (1993b) Effect of a soluble polysaccharide (carboxy methyl cellulose) on the absorption of minerals from the gastrointestinal tract of broilers. Br Poult Sci 34, 985-997.

Waheed AA \& Gupta PD (1997) Changes in structural and functional properties of rat intestinal brush border membrane during starvation. Life Sci 61, 2425-2433.

Wapnir RA, Wingertzahn MA \& Teichberg S (1997) Cellulose derivatives and intestinal absorption of water and electrolytes: potential role in oral rehydration solutions. Proc Soc Exp Biol Med 215, 275-280.

Wyatt GM, Horn N, Gee JM \& Johnson IT (1988) Intestinal microflora and gastrointestinal adaptation in the rat in response to non-digestible dietary polysaccharides. $B r \quad J$ Nutr 60, 197-207. 